Ko, W., Miccinesi, G., Beccaro, M., Moreels, S., Donker, G.A., Onwuteaka-Philipsen, B., Alonso T.V.A.V, Deliens, L., Block, L. van den. Factors associated with fulfilling the preference for dying) at home among cancer patients: the role of general practitioners. Journal of Palliative Care: 7 2014, 30(3), 141-150

\begin{tabular}{|l|l|}
\hline $\begin{array}{l}\text { Postprint } \\
\text { Version }\end{array}$ & 1.0 \\
\hline Journal website & http://criugm.qc.ca/journalofpalliativecare/ \\
\hline Pubmed link & \\
\hline DOI & \\
\hline
\end{tabular}

\title{
Factors Associated with Fulfilling the Preference for Dying at Home among Cancer Patients: The role of general practitioners
}

\author{
Winne Ko, Guido Miccinesi, Monica Beccaro, Sarah Moreels, Gé A. DonKer, \\ BREgJe ONWUTEAKA-PHILIPSEN, TOMÁS V. Alonso, LuC DELIENS, AND LiEVE VAN DEN \\ BLOCK ON BEHALF OF EURO IMPACT
}

W Ko (corresponding author): End-of-Life Care Research Group, Room 126, Building K, Department of Family Medicine, Vrije Universiteit Brussel Laarbeeklaan 103, 1090 Brussels, Belgium; and Ghent University, Ghent, Belgium; winne.ko@vub.ac.be G Miccinesi: Clinical and Descriptive Epidemiology Unit, Cancer Prevention and Research Institute, ISPO,

Florence, Italy: M Beccaro: Regional Palliative Care Network, IRCCS AOU San Martino-IST, Genoa, Italy; S Moreels: Public Health and Surveillance, Scientific Institute of Public Health, Brussels, Belgium;

GA Donker: NIVEL (Netherlands Institute for Health Services Research), Utrecht, Netherlands:

B Onwuteaka-Philipsen: EMGO Institute for Health and Care Research, Department of Public and Occupational Health; and Palliative Care Expertise Centre, VU University Medical Centre, Amsterdam, Netherlands;

TV Alonso: Public Health Directorate General, Health Department, Valencia, Spain;

L Deliens: End-of-Life Care Research Group, Vrije Universiteit Brussel, Brussels, Belgium; Ghent University, Ghent, Belgium; EMGO Institute for Health and Care Research, Department of Public and Occupational Health; and Palliative Care Expertise Centre, VU University Medical Centre, Amsterdam, Netherlands;

L Van den Block: End-of-Life Care Research Group and Department of Family Medicine, Vrije Universiteit Brussel, Brussels, Belgium; and Ghent University, Ghent, Belgium EURO IMPACT collaborators: Lieve Van den Block, Zeger De Groote, Sarah Brearley, Augusto Caraceni, Joachim Cohen, Massimo Costantini, Anneke Francke, Richard Harding, Irene Higginson, Stein Kaasa, Karen Linden, Guido Miccinesi, Bregje OnwuteakaPhilipsen, Koen Pardon, Roeline Pasman, Sophie Pautex, Sheila Payne, and Luc Deliens

\begin{abstract}
Aim: This study aimed to explore clinical and care-related factors associated with fulfilling cancer patients' preference for home death across four countries: Belgium (BE), the Netherlands (NL), Italy (IT), and Spain (ES). Methods: A mortality follow-back study was undertaken from 2009 to 2011 via representative networks of general practitioners (GPs). The study included all patients aged 18 and over who had died of cancer and whose home death
\end{abstract}


Ko, W., Miccinesi, G., Beccaro, M., Moreels, S., Donker, G.A., Onwuteaka-Philipsen, B., Alonson T.V.A.V, Deliens, L., Block, L. van den. Factors associated with fulfilling the preference for dying) at home among cancer patients: the role of general practitioners. Journal of Palliative Care:2014, 30(3), 141-150

preference and place of death were known by the GP. Factors associated with meeting home death preference were tested using multivariable logistic regressions. Results: Among 2,048 deceased patients, preferred and actual place of death was known in 42.6 percent of cases. Home death preference met ranged from 65.5 to 90.9 percent. Countryspecific factors included older age in BE, and decisionmaking capacity and being female in the NL. GPs' provision of palliative care was positively associated with meeting home death preference. Odds ratios (ORs) were: BE: 9.9 (95 percent confidence interval [CI] 3.7-26.6); NL: 9.7 (2.4-39.9); and IT: 2.6 (1.2-5.5). ORs for Spain are not shown because a multivariate model was not performed. Conclusion: Those who develop policy to facilitate home death need to examine available resources for primary end-oflife care.

\section{INTRODUCTION}

Cancer continues to be a leading cause of death in Europe, with an estimated 1.75 million deaths in $2012(1,2)$. During the advanced stage of the disease, multiple complex decisions often have to be made about issues such as shifts in treatment aims and use of palliative care services. In this decision-making process, respect for patient preferences is of great importance; healthcare professionals must end eavour to fulfill those wishes whenever conditions allow (3).

A recent review confirmed that most people - patients, caregivers, and members of the general public - would choose to die at home, and this preference remains stable for four-fifths of patients (4). Across countries, these figures range from 66.1 percent in Spain; to 71.6 percent in Flanders, Belgium; to 76.1 percent in Italy; to 83.1 percent in the Netherlands (5). However, that wish often remains unfulfilled (6). A population based study on cancer patients' place of death in the UK (7) found that hospital remained the most common place of death for many patients. Therefore, meeting cancer patients' preference for a home death continues to be a challenge, and understanding the factors influencing preference met on home death will provide important information about how clinical practices can be improved.

Most existing studies have focused on place of death and its associated factors without taking into account patient preferences. These studies highlight the importance of environmental, illness-related, and individual factors such as family support, gender, and the availability of home care services (8-16). A number of studies have also examined determinants affecting the congruence of place of death, including distance to hospitals and individual preferences (15-17). However, past studies varied in research design, many had small sample sizes, and few provided cross-country perspectives on factors associated with meeting patient preferences. In addition, such factors appeared to have interacted with one another (14), complicating interpretations. Original research focusing on factors related to meeting patients' preference for dying at home is essential if we are to disentangle the mechanism behind the reality.

Despite globalizations and progress in benchmarking, healthcare remains a domain heavily laden with country-specific characteristics (18). It has been argued that localization, including taking into account culture and existing service infrastructure, is vital to the design of successful healthcare policies (19). Since most cancer patients wish to die at home, a cross-country study of the factors associated with 
Ko, W., Miccinesi, G., Beccaro, M., Moreels, S., Donker, G.A., Onwuteaka-Philipsen, B., Alonso T.V.A.V, Deliens, L., Block, L. van den. Factors associated with fulfilling the preference for dying) at home among cancer patients: the role of general practitioners. Journal of Palliative Care: 7 2014, 30(3), 141-150

meeting this preference could contribute to our knowledge of what types of interventions would help in this regard and could thus guide policymakers in planning appropriate end-of-life care.

In this study, utilizing representative GP networks (20), we explored factors associated with cancer patients dying at home, which was their preferred place of death. We hypothesized that factors related to care characteristics would be linked to meeting patients' known preference for a home death.

This study had two aims: to explore clinical and care factors associated with fulfilling preferences for dying at home among cancer patients by means of a mortality follow-back study conducted in Belgium, the Netherlands, Italy, and Spain; and to describe the differences in these factors across the four countries.

\section{METHODS}

\section{Design}

We performed a mortality follow-back study with the European Sentinel GP Networks Monitoring End-of-Life Care (EURO SENTIMELC) 2009-2011 (20092010 in Belgium [BE], the Netherlands [NL], and Italy [IT]; and 2010-2011 in Spain [ES]), which continuously monitored end-of-life care via representative networks of general practitioners (GPs) (20). A sentinel network of GPs can be understood as "a network of general practices or primary care physicians who monitor one, several or an exhaustive list of health problems on a regular or continuing basis” (20). GPs were asked to report the deaths of all their patients aged 18 and older on a weekly basis and report on place of death preference and end-of-life care provided in the final three months of life using a standardized registration form.

\section{Setting and Participants}

The sampled GP networks represented from 0.8 percent (NL) to 4 percent (IT) of the population in the surveyed areas. Networks in all countries except Italy had come into existence long before our project; a new network was established in Italy for this study. All samples were nationwide, except for those of Spain, where only two regions (Castilla y León in the north, and Valencia in the south) were included. Details of these representative GP networks were published previously (19). Using the registration form, GPs indicated whether or not the patient's death was "sudden and totally unexpected." For the present study, we included: patients 18 years of age and older who had experienced non sudden deaths; those who had died of cancer (that is, cancer was the underlying cause of death according to the GP); and those whose actual place of death and home death preference were known by the GP (indicated by responses to the questions "Were you informed of the patient's preference regarding place of death?” and, "If yes, where did this patient prefer to die?”). Information from both verbal and written communications was regarded as valid evidence of a patient's preference for place of death.

Nursing home deaths in the Netherlands were excluded, since in that country, GPs discontinue regular care after a patient's transition to a nursing home (20, 21).

\section{General Practice and Palliative Care in the Four Studied Countries}

In Europe, general practices are highly accessible. In some countries (such as the Netherlands and Spain), GPs are gatekeepers for healthcare delivery, serving as primary care providers who coordinate patient care and offer referrals to specialist services. In other countries (such as Belgium and Italy), they are not gatekeepers, but 
Ko, W., Miccinesi, G., Beccaro, M., Moreels, S., Donker, G.A., Onwuteaka-Philipsen, B., Alonso T.V.A.V, Deliens, L., Block, L. van den. Factors associated with fulfilling the preference for dying) at home among cancer patients: the role of general practitioners. Journal of Palliative Care2014, 30(3), 141-150

they do play a central coordinating role in the healthcare system; almost everyone has a GP whom he or she consults regularly $(20,22)$.

There are hardly any studies describing and comparing the GP's role in palliative care provision in these countries. Earlier reports on palliative care delivery in Belgium and the Netherlands show that GPs consult specialist palliative care providers more often in Belgium and offer palliative care themselves more often in the Netherlands (23). However, according to the latest European Association for Palliative Care Atlas (22), palliative care services are generally covered by the public health system in all countries, so most patients do not have to pay out-of-pocket for access to palliative care services (although they sometimes must pay a small fee for medications).

\section{Data Collection}

Procedure Participating GPs used a weekly, standardized registration form to record deaths occurring in their practices. In order to minimize recall bias, they recorded each death immediately after the patient died. Paper-based registration was administered in Belgium, the Netherlands, and Castilla y León, whereas Web-based registration was adopted in Italy, and an electronic registry was employed in Valencia.

\section{Measurements}

Most items were pooled from the registration forms used in the SENTIMELC study in Belgium and the Netherlands (20, 21, 24). Questions were developed in Dutch and then translated into French and English; from English they were translated into Italian and Spanish through forward backward procedures (20). The questionnaire consisted of 22 questions concerning the final three months of life. They were classified into six domains: places of care and death, transitions between care settings, end-of-life care communications (related to physical and psychological distress), palliative care provision, symptoms in the last week of life, and costs and burdens of end-of-life care.

We tested 12 variables for their association with preference met: age; gender; type of malignancy; the patient's decision-making capacity in the last week of life; communication about palliative care options; the patient's expressed wishes concerning medical treatment; the number of GP contacts with the patient in the period encompassing the fourth, third, and second weeks before death; the GP's provision of palliative care to the patient; initiation of specialist palliative care in the last three months of life; provision of specialist home care; difficulties faced by the patient's family members in covering costs of care; and the perceived burden on the informal caregiver (as observed and judged by the GP).

The GP's provision of palliative care is a modified binary variable response (yes/no) to the question "Did you provide palliative care to this patient?" A “yes" includes both "Yes, until death" and "Yes, but not until death." Two variables were created from the question "Which specialist palliative care initiatives were involved in the last three months of this patient's life?” They contained predefined categorical answers (different for each country, depending on available services). The variable "specialist palliative care initiated" refers to all types of palliative care services, including those available through hospices, palliative care units, day care centres, and home care organizations. "Specialist palliative care at home" is a dichotomous variable (yes/no), and it refers solely to the use of specialist palliative care at home. 
Ko, W., Miccinesi, G., Beccaro, M., Moreels, S., Donker, G.A., Onwuteaka-Philipsen, B., Alonso

T.V.A.V, Deliens, L., Block, L. van den. Factors associated with fulfilling the preference for dying)

at home among cancer patients: the role of general practitioners. Journal of Palliative Care: 7

2014, 30(3), 141-150

\section{Ethical Approval}

Ethical approval for the study, which also covered the consent procedures, was granted in Belgium by the ethical review board of University Hospital Brussels (2004) and in Italy by the local ethical committee in Grosseto (2008). No specific ethical approvals were needed in the Netherlands or Spain because we employed a retrospective, anonymous approach to data collection, and this conforms to local legislation.

\section{Statistical Analyses}

Reported actual and preferred place of death were used to create the variable "preference met," and other questionnaire items were tested as factors associated with preference met for home death.

The analyses explored the potential associated factors of meeting known home death preference.

Bivariate analyses (logistic regression on home preference met or not) were conducted separately for each country and for each of the 12 items selected for analysis. Percentages (proportions of preference met with respect to the categorical variables) were calculated, then the odds ratios (ORs) and 95 percent confidence interval (CI) from the bivariate analyses on each associated factor were reported. Multivariate logistic regressions (backward stepwise) were then fitted separately for each country to identify independent associations of those covariates with preference met. The final model considered the variables that showed a significant association with the studied outcome in the adjusted model on a country-by-country basis. No model was fitted for Spain because of the smaller sample size and lack of variability on some of the variables considered. Interaction terms between the covariates were tested through a likelihood-ratio test. All analyses were completed using Stata 12 (StataCorp, 2011).

\section{RESULTS}

Data for 7,411 deceased patients were collected from four countries between 2009 and 2011.

\section{[FIGURE 1] [TABLE 1] [TABLE 2]}

Of these patients, 2,048 died of cancer, and the GPs of 873 (42.6 percent) of them knew their preference for place of death (Figure 1). A vast majority of the deceased patients - 695 (79.8 percent) — preferred to die at home (BE: 206 [70.8 percent]; NL: 188 [77.4 percent]; IT: 235 [89 percent]; and ES: 66 [90.4 percent]). A palliative care unit or hospice was the second most preferred place of death $(n=85,9.8$ percent). While most patients died at home, hospital deaths ranged from less than onetenth (NL and ES) to over one-third (IT) across the countries.

\section{Patient Sample and Characteristics}

No cross-country differences were found based on gender or malignancy type among the 695 cancer patients who preferred to die at home (Table 1). A higher percentage (22.7 percent) of patients died at age 86 or older in Spain than in the other countries in the study. Across countries, three out of four patients died at age 65 or older. Differences were observed in actual place of death $(\mathrm{p}<.001)$. 
Ko, W., Miccinesi, G., Beccaro, M., Moreels, S., Donker, G.A., Onwuteaka-Philipsen, B., Alonso T.V.A.V, Deliens, L., Block, L. van den. Factors associated with fulfilling the preference for dying) at home among cancer patients: the role of general practitioners. Journal of Palliative Care: 7 2014, 30(3), 141-150

Of those patients preferring to die at home, the proportion who did so ranged from 65.5 percent in Italy, to 73.3 percent in Belgium, to 86.7 percent in the Netherlands, to 90.9 percent in Spain.

\section{Bivariate Analyses of Factors Associated with Preference for Dying at Home Met}

In the bivariate analyses (Table 2), only one variable - GP provision of palliative care - was found to be consistently associated with preference met for two countries (estimation was not possible for Spain, and it was only borderline significant for Italy) (ORs: BE: 9.2 [95 percent CI 3.623.8]; and NL: 7.2 [2.2-23.9]).

Two variables yielded country-specific results.

Gender was associated with preference met in the Netherlands. A Dutch female patient preferring to die at home had a lower chance of doing so than her male counterpart (OR: 0.2 [0.1-0.7]). Having a caregiver — whether the caregiver felt burdened or not - increased a Belgian patient's odds of seeing his or her preference for dying at home met (ORs: 8.9 [1.7-47.2] burdened; and 9.4 [1.8-49.3] not burdened). Estimations for some variables were not possible due to a lack of variability in the data.

Looking more closely at the data (results not shown in the tables), we see that the proportions of patients receiving both GP care and specialist palliative care at home were 59.9 percent in Belgium, 20.0 percent in the Netherlands, and 37.2 percent in Italy. However, 75.3 percent of patients in the Netherlands received GP care exclusively, and the numbers were 40.1 percent and 62.3 percent in Belgium and Italy, respectively. Lastly, 20.8 percent of patients in Belgium and 32.6 percent of patients in Italy were cared for at home only by specialist palliative care teams; no such cases were found in the Netherlands.

\section{Factors Independently Associated with Preference for Dying at Home Met}

Multivariate logistic regressions were performed separately for each country (Table 3). GP provision of palliative care was independently associated with preference met in all countries when other covariates such as age, gender, number of GP contacts in the weeks before death, and the patient's ability to make decisions were controlled for. The strongest associations were found in Belgium (OR: 9.9 [3.7-26.6]), followed by the Netherlands (OR: 9.7 [2.4-39.9]) and Italy (OR: 2.6 [1.2-5.5]).

A few country-specific associations were found.

Older Belgian patients had a lower likelihood of having their home death preference met than did their younger counterparts (age 65 to 85, OR: 0.4 [0.2-0.97]). Two variables were distinctive for Dutch patients: being female significantly reduced a patient's chances of achieving her home death preference (OR: 0.1 [0.04-0.4]), and decision making capacity increased the likelihood of a patient's preference being fulfilled (OR: 6.7 [1.529.0]). In Italy, patients who had two or more contacts with their GPs in the period encompassing the fourth, third, and second weeks before death had a lower chance of having their home death preference met (OR: 0.1 [0.01$0.9])$. 
Ko, W., Miccinesi, G., Beccaro, M., Moreels, S., Donker, G.A., Onwuteaka-Philipsen, B., Alonso

T.V.A.V, Deliens, L., Block, L. van den. Factors associated with fulfilling the preference for dying)

at home among cancer patients: the role of general practitioners. Journal of Palliative Cake-

2014, 30(3), 141-150

\section{[TABLE 3]}

\section{DISCUSSION}

Our results showed that, on average, almost four out of five deceased patients in the surveyed countries whose GPs had been informed about their preference for place of death wanted to die at home, confirming the conventional wisdom about people's preference for home death $(4,10)$.

However, cross-country differences were observed in the actual place of death of these patients - the proportions of those whose preference for a home death was met ranged from 65.5 percent in Italy to 90.9 percent in Spain. This also corresponds to the findings of a previous study, which indicated congruence between preferred and actual place of death ranging from 30 to 90 percent across countries (25). Spain had a high proportion of home deaths (among those whose preference was known) and lower proportions of deaths in hospitals, palliative care units, and hospices. It seems that in Spain, when a GP indicated that he or she was aware of a patient's preference for a home death, care would be coordinated to allow that preference to be fulfilled. However, it was also possible that in some cases, patients were already living home where their care needs were being met, and GPs tried to maintain this arrangement until the end of life. The wishes of patients who were incapable of making decisions were all fulfilled, which implies that these wishes had been previously communicated to the GPs (Table 2); however, such wishes may or may not have been formally documented. Among our sampled cancer patients, those who had received palliative care from their GPs were found to have had a greater chance of seeing their wish to die at home fulfilled in three of the studied countries.

On first reading, this finding would appear to signal the importance of GPs offering palliative care to their patients. However, closer examination suggests that many of these patients saw their wish to die at home fulfilled because they and their families had long-standing relationships with their GPs; this meant that the GPs had a good understanding of the patients' home conditions and thus the knowledge they needed to initiate the essential steps for meeting the preference for a home death.

Alternatively, it could suggest that if dying patients were able to stay at home due to other factors, such as the availability of family support, then GPs could provide athome palliative care, or at least care that they perceived as palliative. Another explanation could be that those patients who clearly expressed a preference to die at home might have had a better-than average relationship with their GPs and could thus depend on their GPs to assist them in that regard. Regardless of the direction of the association between GP palliative care provision and dying in one's preferred place, the results do show that GP palliative care and dying at home are intrinsically related. Policies aimed at supporting people in their choice of where to die should be developed with the role of primary end-of-life care and the availability of end-of-life care resources in mind.

The strength of the association between GP palliative care provision and patients' preference for a home death varied across the countries in the study: it was stronger in Belgium and the Netherlands and weaker in Italy, which could reflect the fact that palliative care is a young discipline in Italy. Future research should study these findings in more depth. Although previous literature suggested that the greater proportion of home deaths in some countries is the result of a lack of access to acute care or palliative care (7), we do not believe that this is the case in the four countries that we studied, since in these places access to general healthcare is free. However, 
Ko, W., Miccinesi, G., Beccaro, M., Moreels, S., Donker, G.A., Onwuteaka-Philipsen, B., Alonso T.V.A.V, Deliens, L., Block, L. van den. Factors associated with fulfilling the preference for dying) at home among cancer patients: the role of general practitioners. Journal of Palliative Care- 7 2014, 30(3), 141-150

other information - such as the geographical distances between patients' homes and acute care facilities, or cultural perceptions of professional care settings - if available, could enhance the understanding of our results by helping to disentangle the relationships between different factors.

Interestingly, receiving specialist palliative care at home was not a factor that was independently associated with the fulfillment of a home death preference. This finding is intriguing because it has been argued that in spite of the growth of palliative care as a discipline, most such care is provided worldwide by GPs $(11,26)$; and, given time and resource constraints, it is unlikely that palliative care specialists would be able to take on all patients requiring palliative care $(27,28)$, further indicating that GPs play a vital role (27-30). These results not only reflect the ways in which the organization of palliative care services differs across countries (31-34), but they may also support the concept of an optimal division of labour between generalists and specialists $(25,35)$.

An integrated plan for palliative care in Valencia, Spain, recommends that patients with more complex conditions and needs receive hospitalbased palliative care along with other services; however, most patients continue to receive palliative care at home from their GPs or palliative home care teams.

Intraregional variations are to be expected, but the fact that differences in service provision coexist with a generally high proportion of home death preference met emphasizes the importance of good communication between GPs and specialist teams, particularly when it comes to making timely referrals (36) and exploring patient preferences in an expedient manner (37).

Country-specific associations that we identified in our data serve to remind us that the translation of study findings into practice should be approached with caution. For example, the association between patients' decision-making capacity and the fulfillment of their place of death preference could be influenced by the medical culture that prevails in the Netherlands, which supports patient autonomy in the endof-life decision making process; this could increase Dutch patients' chances of dying at home if they communicate their preference to healthcare professionals. Another example is found in the data for Italy and merits further investigation if we are to better understand the organization of end-of-life care in that country. We observed that an increased number of GP-patient contacts in the patient's last few weeks of life reduced the chances of the patient's home death preference being met. This raised the possibility that such patients had a greater symptom burden, and thus more needs, and were therefore transferred to hospital to be cared for in the final hours of their lives.

Current literature notes that the presence of certain clinical factors, such as a hematological tumour $(9,38)$ or the need for greater pain and symptom control, decrease one's likelihood of dying in one's preferred place (7). Social factors, such as medical costs and the burden placed on others, were cited as indicators of equitable access to palliative care services $(8,39,40)$. For instance, some patients cannot afford even small out-of-pocket costs for palliative care services, and the availability of informal caregivers can vary. We did not find the same associations, but this was perhaps due to the fact that our study sample was small. It is also possible that the cancer type represented in our sample had an effect - that is, the patients for whom we had data had a relatively low symptom burden and had been 
Ko, W., Miccinesi, G., Beccaro, M., Moreels, S., Donker, G.A., Onwuteaka-Philipsen, B., Alonso T.V.A.V, Deliens, L., Block, L. van den. Factors associated with fulfilling the preference for dying) at home among cancer patients: the role of general practitioners. Journal of Palliative Care:2014, 30(3), 141-150

able to communicate their preferred place of death to their GPs, plus they had access to high-quality palliative care. The country-specific factors, such as decision-making capacity, also reflect findings in the literature about the concept of autonomy in the Netherlands (41) and the reduced chances for older patients of dying at home (42). Finally, home death has been promoted as a major palliative care quality marker by both the research community (43) and policymakers $(10,44)$, yet the notion that home death is the gold standard remains controversial (45), and some people's preferences change over the disease trajectory $(24,46)$. It is important to respect a patient's preferences (47) while taking into account factors such as costs and the burden on informal caregivers (48). This study was about patients' preference for place of death and the factors associated with it, but a better study approach might be to ask patients directly to name their preferred place of death and then determine whether their wishes were fulfilled.

\section{LIMITATIONS}

This study offers an overview of how the preference for a home death among deceased cancer patients was met in four countries, which allowed Ofor crossnational comparisons. Since sentinel GP networks in these countries were nationally and/or regionally representative, they were able to offer us a macro-picture of the way end-of-life care was arranged in these countries. Focusing specifically on the determinants of preference met, the study aimed to determine ways in which current practice could be improved.

However, the study had several limitations.

One such limitation is that only patients whose wish to die at home was known to the GP were included in the analyses, so we could not interpret univocally the relationship between GP provision of palliative care and home death preference met. It is possible that the members of this patient group had a better-than-average relationship with their GPs, which would mean that they could be more explicit in communicating their preferences to their GPs, and this in turn would permit their GPs to care for them at home. Therefore, it is very likely that patients included in the analyses were receiving GP-oriented palliative care, not only making it easier for GPs to elicit place of care and death preferences but also avoiding frequent transitions between settings, making a home death more feasible. The fact that the congruence of home death preference was higher in this study than in others (30 to 90 percent) (25) might also reflect the limitations imposed by using GP as respondents - that is, if a GP does not know a patient's preference for place of death, then that patient is more likely to die in hospital, which, according to other preference studies (49), would in most cases be against his or her wishes It is also important to note that the low proportion of known preferences might point to a more fundamental gap in communicating end-of-life preferences; and, for patients whose home death preference was known but not met, we did not have sufficient information to determine what had happened in their final weeks or days of life that made it no longer feasible for them to die at home.

Moreover, making use of GPs as a source of information is not unproblematic. Costs and the emotional burden of caregivers were measured as perceived by GPs, who might have underestimated or overestimated these factors. Data retrieved in this fashion could be less accurate than patient-reported outcomes or routinely collected administrative data. A prospective study design employing interviews with patients 
Ko, W., Miccinesi, G., Beccaro, M., Moreels, S., Donker, G.A., Onwuteaka-Philipsen, B., Alonso T.V.A.V, Deliens, L., Block, L. van den. Factors associated with fulfilling the preference for dying) at home among cancer patients: the role of general practitioners. Journal of Palliative Care:2014, 30(3), 141-150

and their family members could have helped us to disentangle the role of each aspect of care and thus overcome the majority of these limitations.

Lastly, the questionnaire design did not allow us to know exactly what GPs meant when they claimed to have provided palliative care. Such care could have involved offering referrals to specialist care, making home visits, or engaging in discussions on end-of-life decision making.

GPs in the countries we examined in our study tend to have long-lasting relationships with their patients - often until the end of the patients' lives. Hence, identifications of patients for whom cancer was an underlying cause of death by treating GPs will likely be more reliable sources of information than death certificates filled in by attending specialist (as these certificates often are); the use of such GP patient identifications can thus be seen as a strength of our study.

\section{CONCLUSION}

In spite of differences in the cultures and the healthcare systems of the four countries in our study, 66 to 92 percent of the cancer patients we looked at died at home, their preferred place to die. We discovered that GPs' provision of palliative care is related to the fulfillment of cancer patients' preference for home death across all four countries. This is an important finding, as GPs are expected to play an increasing role in ensuring access to palliative care for all patients. Policies aimed at ensuring that people are able to die where they choose should take the role of primary end-of-life care and the resources available for it into consideration.

\section{ACKNOWLEDGEMENTS}

On behalf of EURO IMPACT: Lieve Van den Block, Zeger De Groote, Sarah Brearley, Augusto Caraceni, Joachim Cohen, Massimo Costantini, Anneke Francke, Richard Harding, Irene Higginson, Stein Kaasa, Karen Linden, Guido Miccinesi, Bregje Onwuteaka-Philipsen, Koen Pardon, Roeline Pasman, Sophie Pautex, Sheila Payne, and Luc Deliens. European Intersectorial and Multidisciplinary Palliative Care Research Training (EURO IMPACT) is funded by the European Union Seventh Framework Programme (FP7/2007-2013, under grant agreement no. 264697). EURO IMPACT aims to develop a multidisciplinary, multiprofessional, and intersectorial educational and research training framework for palliative care research in Europe. It is coordinated by Luc Deliens and Lieve Van den Block of the End-of-Life Care Research Group, Ghent University, Ghent, Belgium, and Vrije Universiteit Brussel, Brussels, Belgium. Other partners are: VU University Medical Center, EMGO Institute for Health and Care Research, Amsterdam, Netherlands; Cicely Saunders Institute, King's College London, London, and the International Observatory on Endof-Life Care, Lancaster University, Lancaster, United Kingdom; Norwegian University of Science and Technology, and the EAPC Research Network, Trondheim, Norway; the Regional Palliative Care Network, IRCCS AOU San Martino-IST, Genoa, and Cancer Research and Prevention Institute, Florence, Italy; the European Union Geriatric Medicine Society, Geneva, Switzerland; and Springer Science and Business Media, Houten, Netherlands. 
Ko, W., Miccinesi, G., Beccaro, M., Moreels, S., Donker, G.A., Onwuteaka-Philipsen, B., Alonso T.V.A.V, Deliens, L., Block, L. van den. Factors associated with fulfilling the preference for dying) at home among cancer patients: the role of general practitioners. Journal of Palliative Cace2014, 30(3), 141-150

\section{REFERENCES}

1. Malvezzi M, Bertuccio $\mathrm{P}$, Levi F, et al. European cancer mortality predictions for the year 2013. Ann Oncol 2013; 24(3): 792800.

2. Ferlay J, Steliarova-Foucher E, Lortet-Tieulent J, et al. Cancer incidence and mortality patterns in Europe: estimates for 40 countries in 2012. Eur J Cancer 2013; 49(6): 13741403.

3. Hofmann JC, Wenger NS, Davis RB, et al. Patient preferences for communication with physicians about end-of-life decisions. SUPPORT Investigators. Study to Understand Prognoses and Preference for Outcomes and Risks of Treatment. Ann Intern Med 1997; 127(1): 1-12.

4. Gomes B, Calanzani N, Gysels M, et al. Heterogeneity and changes in preferences for dying at home: a systematic review. BMC Palliat Care 2013; $12: 7$.

5. Gomes B, Higginson IJ, Calanzani N, et al. Preferences for place of death if faced with advanced cancer: a population survey in England, Flanders, Germany, Italy, the Netherlands, Portugal and Spain. Ann Oncol 2012; 23(8): 2006-2015.

6. Higginson IJ, Sarmento VP, Calanzani N, et al. Dying at home - is it better: a narrative appraisal of the state of the science. Palliat Med 2013; 27(10): 918-924.

7. Gao W, Ho YK, Verne J, et al. Changing patterns in place of cancer death in England: a population-based study. PLoS Med 2013; 10(3): e1001410.

8. Gomes B, Higginson IJ. Factors influencing death at home in terminally ill patients with cancer: systematic review. BMJ 2006; 332(7540): 515-521.

9. Higginson IJ, Costantini M. Dying with cancer, living well with advanced cancer. Eur J Cancer 2008; 44(10): 1414-1424.

10. National End of Life Care Programme (NEoLCP). Critical success factors that enable individuals to die in their preferred place of death. Leicester (UK): NEoLCP; 2012.

11. Hinton $\mathrm{J}$. Which patients with terminal cancer are admitted from home care? Palliat Med 1994; 8(3): 197-210.

12. Grande GE, Addington-Hall JM, Todd CJ. Place of death and access to home care services: are certain patient groups at a disadvantage? Soc Sci Med 1998; 47(5): 565-579.

13. Gatrell AC, Harman JC, Francis BJ, et al. Place of death: analysis of cancer deaths in part of North West England. J Public Health Med 2003; 25(1): 53-58.

14. Wachterman MW, Sommers BD. The impact of gender and marital status on end-of-life care: evidence from the National Mortality Follow-Back Survey. J Palliat Med 2006; 9(2): 343352.

15. Tang ST, McCorkle R. Determinants of congruence between the preferred and actual place of death for terminally ill cancer patients. J Palliat Care 2004; 19(4): 230-237.

16. Bell CL, Somogyi-Zalud E, Masaki KH. Factors associated with congruence between preferred and actual place of death. J Pain Symptom Manage 2010; 39(3): 591-604.

17. Brogaard T, Neergaard MA, Sokolowski I, et al. Congruence between preferred and actual place of care and death among Danish cancer patients. Palliat Med 2012; 27(2): 155-164.

18. Lachenmann G. Globalisation and localisation of health care in poor countries in Africa. Nord-Süd aktuell 2002; 16(3): 456461.

19. Whitehead M, Dahlgren G, Gilson L. Developing the policy response to inequalities in health: a global perspective. In: Evans T, Whitehead M, Diderichsen F, et al., editors. Challenging inequities in health: from ethics to action. New York: Oxford University Press; 2002.

20. Van den Block L, Onwuteaka-Philipsen B, Meeussen K, et al. Nationwide continuous monitoring of end-of-life care via representative networks of general practitioners in Europe. BMC Palliat Care 2013; 14(1): 73.

21. Lynch T, Connor S, Clark D. Mapping levels of palliative care development: a global update. J Pain Symptom Manage 2013; 45(6): 1094-1106.

22. Meeussen K, Van den Block L, Echteld MA, et al. End-of-life care and circumstances of death in patients dying as a result of cancer in Belgium and the Netherlands: a retrospective comparative study. J Clin Oncol 2011; 29(32): 4323-4334. 
Ko, W., Miccinesi, G., Beccaro, M., Moreels, S., Donker, G.A., Onwuteaka-Philipsen, B., Alonso T.V.A.V, Deliens, L., Block, L. van den. Factors associated with fulfilling the preference for dying) at home among cancer patients: the role of general practitioners. Journal of Palliative Cace 2014, 30(3), 141-150

23. Van den Block L, Van Casteren V, Deschepper R, et al. Nationwide monitoring of end-oflife care via the Sentinel Network of General Practitioners in Belgium: the research protocol of the SENTI-MELC study. BMC Palliat Care 2007; $6: 6$.

24. Donker GA. [Continuous morbidity registration Dutch Sentinel General Practice Network 2011.] Annual report. Utrecht: Netherlands Institute for Health Services Research (NIVEL); 2012. [Dutch] 25. Bell CL, Somogyi-Zalud E, Masaki KH. Methodological review: measured and reported congruence between preferred and actual place of death. Palliat Med 2009; 23(6): 482-490.

26. Mitchell GK. How well do general practitioners deliver palliative care? A systematic review. Palliat Med 2002; 16(6): 457-464.

27. Gardiner C, Gott M, Ingleton C. Factors supporting good partnership working between generalist and specialist palliative care services: a systematic review. $\mathrm{Br} \mathrm{J}$ Gen Pract 2012; 62(598): e353-362.

28. Schneider N, Mitchell GK, Murray SA. Palliative care in urgent need of recognition and development in general practice: the example of Germany. BMC Fam Pract 2010; 11: 66. doi: 10.1186/1471-2296-11-66.

29. Bajwah S, Higginson IR. General practitioners' use and experiences of palliative care services: a survey in South East England. BMC Palliat Care 2008; 7: 18. doi: 10.1186/1472684X-7-18.

30. Michiels E, Deschepper R, Van Der Kelen G, et al. The role of general practitioners in continuity of care at the end of life: a qualitative study of terminally ill patients and their next of kin. Palliat Med 2007; 21(5): 409-415.

31. Sbanotto A, Burnhill R. Palliative care in Italy: the current situation. Support Care Cancer 1998; 6(5): 426-429.

32. Desmedt M. Palliative care services in Belgium: benefits and shortcomings of a legal framework. Support Care Cancer 1999; 7(3): 109-112.

33. Desmedt MS, De la Kethulle YL, Deveugele MI, et al. Palliative inpatients in general hospitals: a one day observational study in Belgium. BMC Palliat Care 2011; 10: 2. doi: 10.1186/1472684X-10-2.

34. Gomez-Batiste X, Tuca A, Corrales E, et al. Resource consumptions and costs of palliative care services in Spain: a multicentre prospective study. J Pain Symptom Manage 2006; 31(6): 522-532.

35. Quill TE, Abernethy AP. Generalist plus specialist palliative care: creating a more sustainable model. N Engl J Med 2013; 368(13): 1173-1175.

36. Poulose JV, Do YK, Neo PS. Association between referraltodeath interval and location of death of patients referred to a hospital-based specialist palliative care service. J Pain Symptom Manage 2013; 46(2): 173-181.

37. Galushko M, Romotzky V, Voltz R. Challenges in end-of-life communication. Curr Opin Support Palliat Care 2012; 6(3): 355-364.

38. Hong CY, Chow KY, Poulose J, et al. Place of death and its determinants for patients with cancer in Singapore: an analysis of data from the Singapore Cancer Registry, 20002009. J Palliat Med 2011; 14(10): 1128-1134.

39. Barclay JS, Kuchibhatla M, Tulsky JA, et al. Association of hospice patients' income and care level with place of death. JAMA Intern Med 2013; 173(6): 450-456.

40. Howell DM, Abernathy $\mathrm{T}$, Cockerill R, et al. Predictors of home care expenditures and death at home for cancer patients in an integrated comprehensive palliative home care pilot program. Healthc Policy 2011; 6(3): e73-92.

41. Rietjens JA, van der Heide A, Onwuteaka-Philipsen BD, et al. Preferences of the Dutch general public for a good death and associations with attitudes towards end-of-life decisionmaking. Palliat Med 2006; 20(7): 685-692.

42. Cohen J, Bilsen J, Hooft $P$, et al. Dying at home or in an institution using death certificates to explore the factors associated with place of death. Health Policy 2006; 78(23): 319-329.

43. Houttekier D, Cohen J, Van den Block L, et al. Involvement of palliative care services strongly predicts place of death in Belgium. J Palliat Med 2010; 13(12): 1461-1468.

44. National EOL Framework Forum. Health system reform and care at the end of life: a guidance document. Canberra: Palliative Care Australia; 2010. 
Ko, W., Miccinesi, G., Beccaro, M., Moreels, S., Donker, G.A., Onwuteaka-Philipsen, B., Alonson T.V.A.V, Deliens, L., Block, L. van den. Factors associated with fulfilling the preference for dying at home among cancer patients: the role of general practitioners. Journal of Palliative Care2014, 30(3), 141-150

45. Barclay S, Arthur A. Place of death: how much does it matter? The priority is to improve end-of-life care in all settings. Br J Gen Pract 2008; 58(549): 229-231.

46. Luckett T, Davidson PM, Lam L, et al. Do community specialist palliative care services that provide home nursing increase rates of home death for people with life-limiting illnesses? A systematic review and meta-analysis of comparative studies. J Pain Symptom Manage 2013; 45(2): 279-297.

47. Borreani C, Miccinesi G. End of life care preferences. Curr Opin Support Palliat Care 2008; 2(1): 54-59.

48. Stajduhar KI, Martin WL, Barwich D, et al. Factors influencing family caregivers' ability to cope with providing end-of-life cancer care at home. Cancer Nurs 2008; 31(1): 77-85.

49. Ko W, Beccaro M, Miccinesi G, et al. Awareness of general practitioners concerning cancer patients' preferences for place of death: evidence from four European countries. Eur J Cancer 2013; 49(8): 1967-1974.

\section{TABLES AND FIGURES}

Figure 1 / Flow Chart

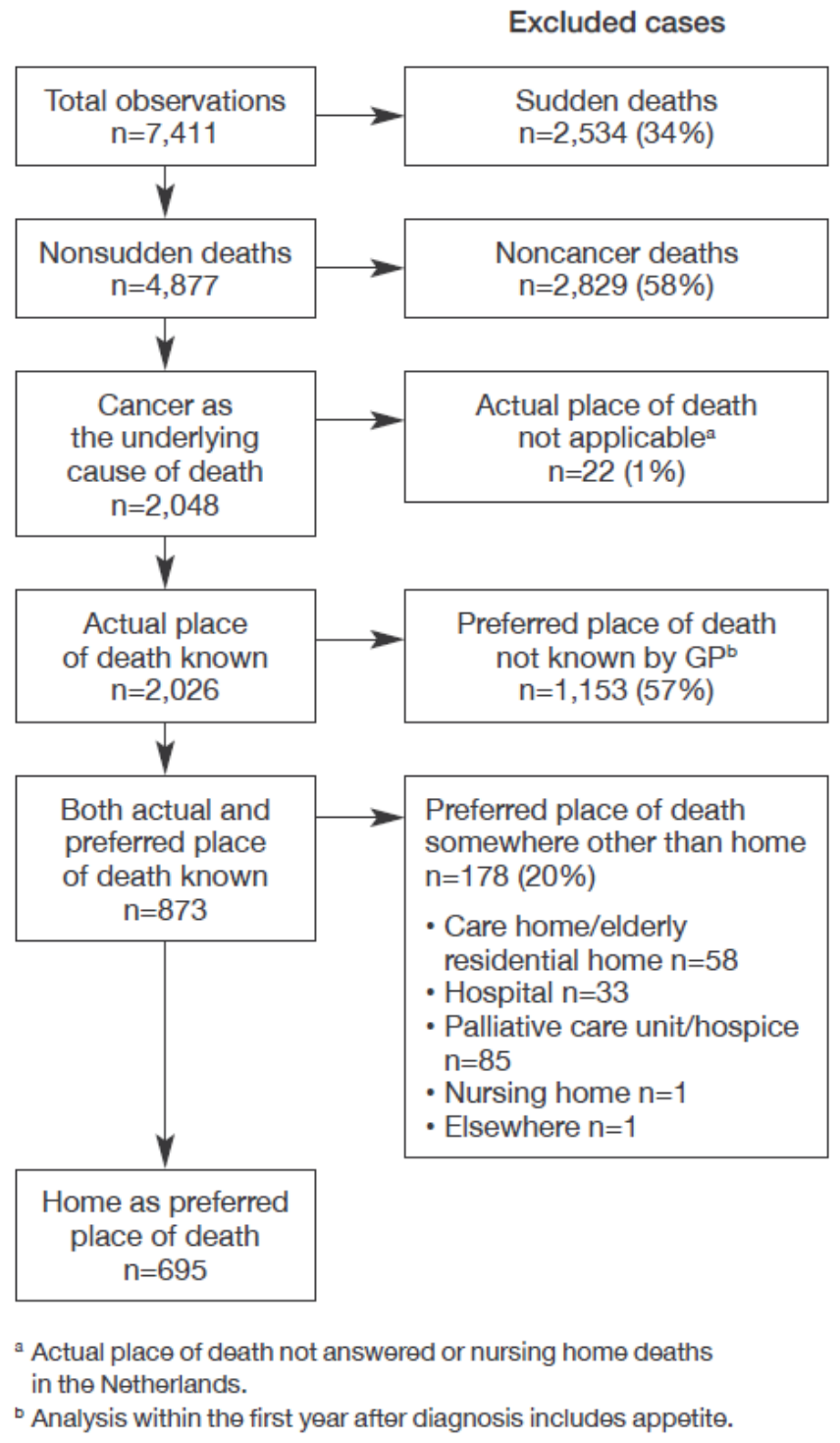


Ko, W., Miccinesi, G., Beccaro, M., Moreels, S., Donker, G.A., Onwuteaka-Philipsen, B., Alonson T.V.A.V, Deliens, L., Block, L. van den. Factors associated with fulfilling the preference for dying at home among cancer patients: the role of general practitioners. Journal of Palliative Care: 7 2014, 30(3), 141-150

Table 1 / Characteristics of Cancer Patients with a Home Death Preference, as Known by the GP (n=695)

\begin{tabular}{|c|c|c|c|c|c|}
\hline & $\begin{array}{l}\text { Belgium } \\
(n=206)\end{array}$ & $\begin{array}{l}\text { Netherlands } \\
\quad(n=188)\end{array}$ & $\begin{array}{c}\text { Italy } \\
(n=235)\end{array}$ & $\begin{array}{l}\text { Spain } \\
(n=66)\end{array}$ & p-value ${ }^{a}$ \\
\hline $\begin{array}{l}\text { Age group } \\
18-64 \\
65-85 \\
86 \text { or older }\end{array}$ & $\begin{array}{c}\mathrm{n}(\%) \\
66(32.2) \\
111(54.2) \\
28(13.7)\end{array}$ & $\begin{array}{c}\mathrm{n}(\%) \\
51(27.1) \\
118(62.8) \\
19(10.1)\end{array}$ & $\begin{array}{c}\mathrm{n}(\%) \\
49(20.9) \\
144(61.3) \\
42(17.9)\end{array}$ & $\begin{array}{c}\mathrm{n}(\%) \\
14(21.2) \\
37(56.1) \\
15(22.7)\end{array}$ & $\mathrm{p}=0.021$ \\
\hline $\begin{array}{l}\text { Gender }^{c} \\
\text { Male } \\
\text { Female }\end{array}$ & $\begin{array}{r}116(56.3) \\
90(43.7)\end{array}$ & $\begin{array}{l}96(51.6) \\
90(48.4)\end{array}$ & $\begin{array}{r}138(58.7) \\
97(41.3)\end{array}$ & $\begin{array}{l}42(63.6) \\
24(36.4)\end{array}$ & $\mathrm{p}=0.302$ \\
\hline $\begin{array}{l}\text { Type of Malignancy } \\
\text { Lung } \\
\text { Breast } \\
\text { Colorectal } \\
\text { Prostate } \\
\text { Other }\end{array}$ & $\begin{array}{c}54(26.2) \\
14(6.8) \\
27(13.1) \\
10(4.9) \\
101(49.0)\end{array}$ & $\begin{array}{l}42(23.2) \\
17(9.4) \\
23(12.7) \\
13(7.2) \\
86(47.5)\end{array}$ & $\begin{array}{l}51(25.9) \\
14(7.1) \\
25(12.7) \\
11(5.6) \\
96(48.7)\end{array}$ & $\begin{array}{c}10(15.4) \\
4(6.2) \\
15(23.1) \\
8(12.3) \\
28(43.1)\end{array}$ & $\mathrm{p}=0.341$ \\
\hline $\begin{array}{l}\text { Place of death } \\
\text { Home (home preference met proportions) } \\
\text { Care home/residential home for the elderly } \\
\text { Hospital } \\
\text { Palliative care unit/hospice } \\
\text { Elsewhere }\end{array}$ & $\begin{array}{c}151(73.3) \\
3(1.5) \\
26(12.6) \\
25(12.1) \\
1(0.5)\end{array}$ & $\begin{array}{c}163(86.7) \\
2(1.1) \\
15(8.0) \\
8(4.3) \\
-\end{array}$ & $\begin{array}{c}154(65.5) \\
3(1.3) \\
70(29.8) \\
8(3.4) \\
-\end{array}$ & $\begin{array}{l}60(90.9) \\
- \\
5(7.6) \\
1(1.5) \\
-\end{array}$ & $p<0.001$ \\
\hline
\end{tabular}

${ }^{a} \chi^{2}$ test on cross-country differences.

${ }^{\mathrm{b}}$ Missing: $\mathrm{n}=1$.

${ }^{\mathrm{c}}$ Not answered: $\mathrm{n}=2$.

Missing or not answered: $n=46$. 
Ko, W., Miccinesi, G., Beccaro, M., Moreels, S., Donker, G.A., Onwuteaka-Philipsen, B., Alonso T.V.A.V, Deliens, L., Block, L. van den. Factors associated with fulfilling the preference for dying) at home among cancer patients: the role of general practitioners. Journal of Palliative Care:

Table 2 / Bivariate Analyses of Factors Associated with Fulfilling Preference for Dying at Home, as Known by the GP $(n=695)$

\begin{tabular}{|c|c|c|c|c|c|c|c|c|}
\hline \multirow[b]{2}{*}{ Variables" } & \multicolumn{2}{|r|}{$\begin{array}{l}\text { Belgium } \\
\text { ( } n=206)\end{array}$} & \multicolumn{2}{|c|}{$\begin{array}{l}\text { Netherlands } \\
(n=188)\end{array}$} & \multicolumn{2}{|r|}{$\begin{array}{c}\text { Italy } \\
(n=235)\end{array}$} & \multicolumn{2}{|r|}{$\begin{array}{l}\text { Spain } \\
(n=66)\end{array}$} \\
\hline & $\%$ & $\mathrm{OR}^{\mathrm{c}}\left(95 \% \mathrm{Cl}^{d}\right)$ & $\%$ & OR $(95 \% \mathrm{Cl})$ & $\%$ & OR $(95 \% \mathrm{Cl})$ & $\%^{\mathrm{b}}$ & OR $(95 \% \mathrm{Cl})$ \\
\hline $\begin{array}{l}\text { Age group } \\
18-64 \\
65-85 \\
86 \text { or above }\end{array}$ & $\begin{array}{l}83.3 \\
70.3 \\
64.3\end{array}$ & $\begin{array}{c}\text { ref } \\
0.5(0.2-1.0) \\
0.4(0.1-1.0)\end{array}$ & $\begin{array}{l}86.3 \\
89.0 \\
73.7\end{array}$ & $\begin{array}{c}\text { ref } \\
1.3(0.5-3.4) \\
0.4(0.1-1.6)\end{array}$ & $\begin{array}{l}61.2 \\
66.0 \\
69.1\end{array}$ & $\begin{array}{c}\text { ref } \\
1.2(0.6-2.4) \\
1.4(0.6-3.4)\end{array}$ & $\begin{array}{l}78.6 \\
97.3 \\
86.7\end{array}$ & $\begin{array}{c}\text { ref } \\
9.8(0.9-104.2) \\
1.8(0.2-12.6)\end{array}$ \\
\hline $\begin{array}{l}\text { Gender } \\
\text { Male } \\
\text { Female }\end{array}$ & $\begin{array}{l}71.6 \\
75.6\end{array}$ & $\begin{array}{c}\text { ref } \\
1.2(0.6-2.3)\end{array}$ & \begin{tabular}{|l|}
93.8 \\
78.9
\end{tabular} & $\begin{array}{c}\text { ref } \\
0.2(0.1-0.7)\end{array}$ & $\begin{array}{l}65.9 \\
65.0\end{array}$ & $\begin{array}{c}\text { ref } \\
0.96\langle 0.6-1.7\rangle\end{array}$ & $\begin{array}{l}88.1 \\
95.8\end{array}$ & $\begin{array}{c}\text { ref } \\
3.1(0.3-28.3)\end{array}$ \\
\hline $\begin{array}{l}\text { Type of malignancy } \\
\text { Lung } \\
\text { Breast } \\
\text { Colorectal } \\
\text { Prostate } \\
\text { Other }\end{array}$ & $\begin{array}{l}81.5 \\
71.4 \\
70.4 \\
80.0 \\
69.3\end{array}$ & $\begin{array}{c}\text { ref } \\
0.6(0.1-2.2) \\
0.5(0.2-1.6) \\
0.9(0.2-5.0) \\
0.5(0.2-1.1)\end{array}$ & $\begin{array}{l}88.1 \\
88.2 \\
82.6 \\
92.3 \\
84.9\end{array}$ & $\begin{array}{c}\text { ref } \\
1.0(0.2-5.8) \\
0.6(0.2-2.7) \\
1.6(0.2-15.3) \\
0.8(0.3-2.3)\end{array}$ & $\begin{array}{l}68.6 \\
71.4 \\
72.0 \\
81.8 \\
58.3\end{array}$ & \begin{tabular}{|c|} 
ref \\
$1.1(0.3-4.2)$ \\
$1.2(0.4-3.4)$ \\
$2.1(0.4-10.6)$ \\
$0.6(0.3-1.3)$
\end{tabular} & $\begin{array}{l}90.0 \\
100 \\
93.3 \\
75.0 \\
92.9\end{array}$ & $\begin{array}{c}\text { ref } \\
\text { not estimated } \\
1.6(0.1-28.1) \\
0.3(0.02-4.5) \\
1.4(0.1-17.9)\end{array}$ \\
\hline $\begin{array}{l}\text { Decision-making capability } \\
\text { No } \\
\text { Yes/sometimes }\end{array}$ & $\begin{array}{l}71.4 \\
75.7\end{array}$ & $\begin{array}{c}\text { ref } \\
1.2(0.5-3.0)\end{array}$ & \begin{tabular}{|l|}
69.2 \\
88.5
\end{tabular} & $\begin{array}{c}\text { ref } \\
3.4(0.96-12.2)\end{array}$ & $\begin{array}{l}64.2 \\
67.9\end{array}$ & $\begin{array}{c}\text { ref } \\
1.2(0.6-2.3)\end{array}$ & $\begin{array}{c}100 \\
86.4\end{array}$ & $\begin{array}{c}\text { ref } \\
\text { not estimated }\end{array}$ \\
\hline $\begin{array}{l}\text { Communication of pallitive care options } \\
\text { No } \\
\text { Yes }\end{array}$ & $\begin{array}{l}65.2 \\
73.6\end{array}$ & $\begin{array}{c}\text { ref } \\
1.5(0.6-3.7)\end{array}$ & \begin{tabular}{|l|}
83.3 \\
86.6
\end{tabular} & $\begin{array}{c}\text { ref } \\
1.3\langle 0.1-11.5\}\end{array}$ & $\begin{array}{l}65.8 \\
66.4\end{array}$ & $\begin{array}{c}\text { ref } \\
1.0(0.6-1.8)\end{array}$ & $\begin{array}{l}90.0 \\
89.1\end{array}$ & $\begin{array}{c}\text { ref } \\
0.9(0.1-8.8)\end{array}$ \\
\hline $\begin{array}{l}\text { Wishes about treatment } \\
\text { No } \\
\text { Yec }\end{array}$ & $\begin{array}{l}71.4 \\
74.8\end{array}$ & $\begin{array}{c}\text { ref } \\
1.2(0.6-2.3)\end{array}$ & \begin{tabular}{|l|}
83.8 \\
88.1
\end{tabular} & $\begin{array}{c}\text { ref } \\
1.4(0.5-3.9)\end{array}$ & $\begin{array}{l}63.1 \\
67.1\end{array}$ & $\begin{array}{c}\text { ref } \\
1.2(0.7-2.2)\end{array}$ & $\begin{array}{l}91.3 \\
84.6\end{array}$ & $\begin{array}{c}\text { ref } \\
0.5(0.1-3.2)\end{array}$ \\
\hline $\begin{array}{l}\text { Average number of GP contacts in the } \\
\text { 2nd, 3rd, and } 4 \text { th weeks before death } \\
0 \\
0<n<2 \\
2 \text { or more }\end{array}$ & $\begin{array}{l}64.7 \\
70.6 \\
80.0\end{array}$ & $\begin{array}{c}\text { ref } \\
1.3(0.4-3.8) \\
2.2(0.7-6.9)\end{array}$ & \begin{tabular}{|l|}
75.0 \\
87.5 \\
88.0
\end{tabular} & $\begin{array}{c}\text { ref } \\
2.3(0.6-9.0) \\
2.4(0.7-8.7)\end{array}$ & $\begin{array}{l}90.9 \\
71.2 \\
60.9\end{array}$ & $\begin{array}{c}\text { ref } \\
0.2(0.03-2.1) \\
0.2(0.02-1.2\}\end{array} \mid$ & $\begin{array}{l}100 \\
87.1 \\
93.3\end{array}$ & $\begin{array}{c}\text { ref } \\
\text { not estimated } \\
\text { not estimated }\end{array}$ \\
\hline $\begin{array}{l}\text { GPs'provision of pellitative care } \\
\text { No } \\
\text { Yes }\end{array}$ & $\begin{array}{l}29.2 \\
79.1\end{array}$ & $\begin{array}{c}\text { ref } \\
9.2(3.6-23.8)\end{array}$ & \begin{tabular}{|l|}
53.9 \\
89.4
\end{tabular} & $\begin{array}{c}\text { ref } \\
7.2(2.2-23.9)\end{array}$ & $\begin{array}{l}53.5 \\
68.6\end{array}$ & $\begin{array}{c}\text { ref } \\
1.9(1.0-3.7)\end{array}$ & \begin{tabular}{r|}
100 \\
90.2
\end{tabular} & $\begin{array}{c}\text { ref } \\
\text { not estimated }\end{array}$ \\
\hline $\begin{array}{l}\text { Specialist palliative care initiated } \\
\text { No } \\
\text { Yes }\end{array}$ & $\begin{array}{l}81.2 \\
69.3\end{array}$ & $\begin{array}{c}\text { ref } \\
0.5(0.3-1.1)\end{array}$ & \begin{tabular}{|l|}
89.8 \\
80.3
\end{tabular} & $\begin{array}{c}\text { ref } \\
0.5(0.2-1.1)\end{array}$ & $\begin{array}{l}71.9 \\
61.2\end{array}$ & $\begin{array}{c}\text { ref } \\
0.6(0.4-1.1)\end{array}$ & $\begin{array}{l}96.3 \\
87.2\end{array}$ & $\begin{array}{c}\text { ref } \\
0.3(0.03-2.4)\end{array}$ \\
\hline $\begin{array}{l}\text { Specialist palliative care at home } \\
\text { No } \\
\text { Yec }\end{array}$ & $\begin{array}{l}64.8 \\
80.7\end{array}$ & $\begin{array}{c}\text { ref } \\
1.5(0.8-2.6)\end{array}$ & \begin{tabular}{|l|}
84.9 \\
91.2
\end{tabular} & $\begin{array}{c}\text { ref } \\
2.0(0.7-5.9)\end{array}$ & $\begin{array}{l}65.3 \\
67.1\end{array}$ & $\begin{array}{c}\text { ref } \\
0.9(0.6-1.3)\end{array}$ & $\begin{array}{l}92.1 \\
89.3\end{array}$ & $\begin{array}{c}\text { ref } \\
0.7(0.1-3.8)\end{array}$ \\
\hline $\begin{array}{l}\text { Difficulty for family to cover costs of care } \\
\text { Difficult/very difficult } \\
\text { Not difficult at all } \\
\text { Patient did not nesd care }\end{array}$ & $\begin{array}{c}80.0 \\
74.5 \\
100\end{array}$ & $\mid \begin{array}{c}\text { ref } \\
0.7(0.3-1.8) \\
\text { not estimated }\end{array}$ & $\begin{array}{l}86.5 \\
84.7 \\
82.6\end{array}$ & $\begin{array}{c}\text { ref } \\
0.9(0.3-2.2) \\
0.7(0.2-2.6)\end{array}$ & $\begin{array}{l}59.8 \\
71.1 \\
50.0\end{array}$ & $\mid \begin{array}{c}\text { ref } \\
1.7(0.9-2.9) \\
0.7(0.04-11.1)\end{array}$ & \begin{tabular}{r|}
100 \\
87.8 \\
92.9
\end{tabular} & $\begin{array}{c}\text { ref } \\
\text { not estimated } \\
\text { not estimated }\end{array}$ \\
\hline $\begin{array}{l}\text { Burden of informal caregiver } \\
\text { No caregiver } \\
\text { Caregiver feeling burdened } \\
\text { Caregiver not feeling burdened }\end{array}$ & $\begin{array}{l}25.0 \\
74.7 \\
75.7\end{array}$ & $\begin{array}{c}\text { ref } \\
8.9(1.7-47.2) \\
9.4(1.8-49.3)\end{array}$ & \begin{tabular}{|l|}
$\mathrm{n} / \mathrm{a}^{a}$ \\
83.1 \\
89.7
\end{tabular} & $\mid \begin{array}{c}\text { ref } \\
0.6(0.2-1.4) \\
\text { not estimated }\end{array}$ & $\begin{array}{l}81.8 \\
63.8 \\
77.8\end{array}$ & $\begin{array}{c}\text { ref } \\
0.4(0.1-1.9) \\
0.8(0.1-4.4)\end{array}$ & $\begin{array}{l}n / a^{a} \\
93.1 \\
87.9\end{array}$ & $\begin{array}{c}\text { ref } \\
1.9(0.3-11.0) \\
\text { not } \theta s t i m a t e d\end{array}$ \\
\hline
\end{tabular}

- Missing: age: $n=1$; gender: $n-2$; type of malgnancy: n-46; decision-making capability: n-32; communication of palliative care options: $n=35$; wishes about trestment: $n=44$; GPs' provision of palliative care untl death $n=6$; specialist pelliative home care: $n=12$; difficulty for families

to cover costs of care: $n-63$; and burden of informal carogiver: $n=35$.

'Row percentages of preference met.

Odds ratio. ORs in bold are statistically sigrificarnt at pe0.06.

¿ Confidence interval.

- Reference group in the multivariate logistic regressions.

"Not estimated: there was insufficient variation in the cutcome variable to make estimates of correlatione; one category of the variable

has 100 percent of preference met.

a Not applicable: no observation was found in the category of a variable. 
Ko, W., Miccinesi, G., Beccaro, M., Moreels, S., Donker, G.A., Onwuteaka-Philipsen, B., Alonson T.V.A.V, Deliens, L., Block, L. van den. Factors associated with fulfilling the preference for dying at home among cancer patients: the role of general practitioners. Journal of Palliative Care- 7

\section{Table 3 / Multivariate Analyses of Factors Associated with Fulfilling Preference of Dying at Home, as Known by the GP $(n=629)$}

\begin{tabular}{|c|c|c|c|}
\hline & $\begin{array}{l}\text { Belgium } \\
(n=206)\end{array}$ & $\begin{array}{l}\text { Netherlands } \\
(n=188)\end{array}$ & $\begin{array}{c}\text { Italy } \\
(n=235)\end{array}$ \\
\hline Variables $^{a}$ & $\mathrm{OR}^{\mathrm{b}}\left(95 \% \mathrm{Cl}^{\mathrm{c}}\right)$ & OR ( $95 \% \mathrm{Cl})$ & OR $(95 \% \mathrm{Cl})$ \\
\hline $\begin{array}{l}\text { Age group } \\
18-64 \\
65-85 \\
86 \text { or older }\end{array}$ & $\begin{array}{c}\text { ref }^{d} \\
0.4(0.2-0.97) \\
0.4(0.1-1.1)\end{array}$ & $\begin{array}{l}\text { ref } \\
- \\
-\end{array}$ & $\begin{array}{l}\text { ref } \\
- \\
-\end{array}$ \\
\hline $\begin{array}{l}\text { Gender } \\
\text { Female }\end{array}$ & - & $0.1(0.04-0.4)$ & - \\
\hline $\begin{array}{l}\text { GPs' provision } \\
\text { of palliative care } \\
\text { Yes }\end{array}$ & $9.9(3.7-26.6)$ & $9.7(2.4-39.9)$ & $2.6(1.2-5.5)$ \\
\hline $\begin{array}{l}\text { Average number } \\
\text { of GP contacts } \\
\text { in the } 2 \text { nd, } 3 r d \text {, } \\
\text { and } 4 \text { th weeks } \\
\text { before death } \\
0 \\
0<\mathrm{n}<2 \\
2 \text { or more }\end{array}$ & $\begin{array}{l}\text { ref } \\
- \\
-\end{array}$ & $\begin{array}{l}\text { ref } \\
- \\
-\end{array}$ & $\begin{array}{c}\text { ref } \\
0.2(0.02-1.8) \\
\mathbf{0 . 1}(\mathbf{0 . 0 1 - 0 . 9 )}\end{array}$ \\
\hline $\begin{array}{l}\text { Decision-making } \\
\text { capability } \\
\text { Yes/sometimes }\end{array}$ & - & $6.7(1.5-29.0)$ & - \\
\hline
\end{tabular}

a Missing: age: $n=1$; gender: $n=2$; GPs' provision of palliative care until death: $n=6$

${ }^{\mathrm{b}}$ Odds ratio. ORs in bold are statistically significant at $\mathrm{p}<0.05$.

${ }^{c}$ Confidence interval.

${ }^{d}$ Reference group in the logistic regression (e.g. for the variable age in Belgium, comparisons are made between aged 18-64 and aged 65-85 or aged $18-64$ and aged 85 or older) 